\title{
INFLUENCIA DEL PENSAMIENTO ETNOLÓGICO EN LA INTERPRETACIÓN DE LEROI-GOURHAN DEL ARTE PALEOLÍTICO*
}

\author{
INFLUENCE OF ETHNOLOGICAL THINKING \\ ON LEROI-GOURHAN'S UNDERSTANDING OF PALAEOLITHIC ART
}

\author{
Eduardo Palacio PÉrez** \\ UNED-Cantabria \\ Óscar Moro Abadía \\ Memorial University of Newfoundland
}

\begin{abstract}
RESUMEN. André Leroi-Gourhan participó en el proceso de modernización que experimentó la prehistoria francesa a mediados del siglo xx. En este contexto trabajó para construir una ciencia prehistórica interdisciplinar que quedara incluida dentro del campo epistemológico de la etnología. En este artículo indagamos en cómo afectó la aproximación que este investigador estableció entre prehistoria y etnología a su comprensión del arte paleolítico. Esta conexión se hace especialmente significativa en la influencia que su maestro, el etnólogo francés Marcel Mauss, tuvo en la conformación de su pensamiento sobre el comportamiento artístico, y en cómo André Leroi-Gourhan trasladó estas ideas al estudio y análisis del arte paleolítico. Adicionalmente discutimos la diferente acogida que tuvieron estas nuevas concepciones sobre el arte prehistórico en las tradiciones arqueológicas francesa, espańola y anglosajona. Por último, discutimos si la nueva perspectiva que introdujo Leroi-Gourhan del arte prehistórico desde nociones procedentes de la etnología puede explicarse a partir del concepto de interdisciplinariedad.

PALABRAS CLAVE: Prehistoria, etnología, interdisciplinariedad, arte paleolítico, Marcel Mauss, André Leroi-Gourhan.

ABSTRACT. André Leroi-Gourhan took part in the modernization process experienced by French prehistory in the midtwentieth century. In this context, he worked hard to build an interdisciplinary prehistoric science with strong links with anthropology and ethnology. In this paper, we examine how Leroi-Gourhan's interpretation of Palaeolithic art was shaped by his understanding of the relationships between prehistory and ethnology. This is particularly evident, for instance, in the influence that French ethnologist Marcel Mauss exerted upon Leroi-Gourhan's thinking on artistic behavior. Similarly, André Leroi-Gourhan understanding of Palaeolithic art was grounded on a number of ethnological ideas. Additionally, we discuss the reception that these new conceptions of prehistoric art had in French, Spanish and Anglo-Saxon archaeological traditions. Finally, we examine whether the new perspective of prehistoric art that Leroi-Gourhan introduced in the 1960s can be examined with reference to the concept of interdisciplinarity.
\end{abstract}

KEYWORDS: Prehistory, ethnology, interdisciplinarity, palaeolithic art, Marcel Mauss, André Leroi-Gourhan.

* Este trabajo ha sido realizado en el marco del proyecto de investigación MINECO-Ministerio de Economía y Competitividad «Arqueología e Interdisciplinariedad: una investigación arqueológica-histórica sobre las relaciones interdisciplinares en la Historia de la Arqueología española (siglos XIX y xx)» (HAR2016-80271-P, IP M. Díaz-Andreu) subvencionado por la AEI/FEDER, UE.

\footnotetext{
** Correspondencia a / Correspondence to: Eduardo Palacio Pérez, UNED-Cantabria (Universidad de Educación a Distancia, Centro asociado Santander) - edupalacio@santander.uned.es - https://orcid.org/0000-0002-5427-0618.

Cómo citar / How to cite: Palacio Pérez, Eduardo; Moro Abadía, Óscar (2020), «lnfluencia del pensamiento etnológico en la interpretación de LeroiGourhan del arte paleolítico", Veleia, 37, 141-156. (https://doi.org/10.1387/veleia.20965).
}

Recibido: 27 junio 2019; aceptado: 21 noviembre 2019.

ISSN 0213-2095 - elSSN 2444-3565 / (C) 2020 UPV/EHU 


\section{Introducción. ENTRE LA PREHISTORIA y LA ETNOLOGÍA}

En 1968 André Leroi-Gourhan escribió: «me parece muy sensato [...] que la ciencia del hombre sea la más interdisciplinar de todas» (Leroi-Gourhan 1968a, 1817). Así, expresó su deseo de construir una ciencia que sintetizara diferentes perspectivas para estudiar el comportamiento humano. Para Leroi-Gourhan esta ciencia estaba integrada por seis disciplinas que incluían la etnografía, la antropología física, la sociología, la historia de las religiones, la arqueología, la prehistoria y la lingüística. Todas ellas debían de poder agruparse en una sola palabra, "siendo preferible usar el término etnología» (Leroi-Gourhan 1945, 26). De esta forma, Leroi-Gourhan definió un entorno de reflexión en el que la prehistoria quedaba indefectiblemente unida a la etnología (Baffier et al. 1988). Para el autor francés la prehistoria y la etnología constituyeron una sola ciencia con el «objetivo de establecer una historia de la humanidad que abrace formas extremas, primitivas y evolucionadas, en una visión total» (Leroi-Gourhan 1961, 217).

Sin embargo, esta aspiración de Leroi-Gourhan de vincular ambas materias puede que no encaje de una forma precisa con el concepto de interdisciplinariedad, entendido como la ordenación unitaria de un campo de estudio que cruza fronteras tradicionales entre disciplinas académicas bien establecidas (Nissani 1995). En efecto, cuando Leroi-Gourhan desarrolló estas ideas, la prehistoria no contaba con un ámbito académico bien definido, de hecho, este estaba en proceso de creación en Francia (en otros países ver Callmer et al. 2006). En el contexto de los años centrales del siglo xx Leroi-Gourhan fue uno de los protagonistas de lo que se ha dado en llamar la formación de la prehistoria moderna francesa (Coye 2011, 215-217; 2015; Díaz-Andreu 2012, 581-582; Gaucher 1993). Se trata de un periodo de redefinición de la prehistoria en Francia que afectó a sus conceptos, prácticas e instituciones. Durante la primera mitad del siglo xx la prehistoria se organizó en torno a instituciones no académicas, como las sociedades científicas locales, la Société préhistorique française, el Institut de paléontologie humaine, el Collège de France, y el Museum d'histoire naturelle (Coye 2011). Sin embargo, será tras la II Guerra Mundial cuando la prehistoria francesa inicie su proceso de institucionalización académica tanto en el ámbito universitario como en el del Centre national de la recherche scientifique (CNRS). En la esfera universitaria, la instauración de la prehistoria se produjo de una forma gradual. En 1945 Leroi-Gourhan se encargó de un curso de prehistoria en el Institut d'Ethnologie de la Sorbona, en 1955 se creó la primera cátedra de prehistoria en la Universidad de Toulouse y en 1956 François Bordes fundó el Institut de Préhistoire et de Géologie du Quaternaire en la Universidad de Burdeos. Ese mismo año Leroi-Gourhan ocupó la Cátedra de Etnología de la Sorbona, desde donde organizó en 1960 el Centre de recherches préhistoriques et protohistoriques, y en 1969 se hizo cargo de la Cátedra de Prehistoria en el Collège de France (Coye 2011; 2015; Díaz-Andreu 2012; Soulier 2003, 205).

En el medio universitario la prehistoria experimentó un fenómeno de bipolarización con la creación de las «escuelas» de Burdeos y París, encarnada la primera por François Bordes y la segunda por André Leroi-Gourhan (Coye 2015, 137-143). Entre ambas «escuelas» existieron multitud de diferencias en cuanto al método estratigráfico, el estudio de la tipología y la tecnología, la metodología de excavación y la pertinencia de los estudios de arte rupestre. Estas divergencias científicas expresaban el antagonismo de dos concepciones globales de la disciplina. La de Bordes, apegada a la geología y a las ciencias de la naturaleza, y la de Leroi-Gourhan, asociada a la etnología y las ciencias humanas. Por su parte, la prehistoria también experimentó este fenómeno de división dentro del CNRS. Así, tras su reorganización en 1945, promovida por Fréderic Joliot-Curie, la prehistoria quedó segmentada en dos secciones diferentes: la sección 15 con geología y paleontología, y la sección 20 con etnología y antropología física (Audouze 2003). En este contexto de cons- 
titución académica de la disciplina, Leroi-Gourhan hizo una propuesta de definición integral de la prehistoria, abarcando sus conceptos, métodos y espacio institucional. Es dentro de este proceso dinámico de creación, lleno de tensiones entre distintas formas de entender la disciplina, en el que hay que situar la aproximación que Leroi-Gourhan hizo entre prehistoria y etnología.

A partir de este análisis revisionista de la obra de Leroi-Gourhan, en este artículo indagamos en las raíces de su explicación del arte paleolítico. Esto ha orientado nuestro trabajo hacia sus años de formación y a resaltar el papel de su maestro, el etnólogo Marcel Mauss (1872-1950), en la conformación de su pensamiento sobre el comportamiento artístico. Leroi-Gourhan siempre reconoció el legado de Mauss (Leroi-Gourhan 1945, 25; 1982b, 31-35). Sin embargo, este reconocimiento no implica que entre maestro y alumno no hubiera desacuerdos y malentendidos (Schlanger 2015, 105). Esta vinculación entre Leroi-Gourhan y Mauss se ha establecido en el campo de la tecnología (Audouze 1999; Dobres 1999; Olivier 1999; Schlanger 2015; 2017), la museología etnográfica (Conklin 2013; Schlanger 2016) y la estética (Bidet 2007; Karsenti 1998; Schnapp \& Lemonnier 2009). Sin embargo, aquí profundizamos en la conexión maussiana de las principales ideas sobre las cuales Leroi-Gourhan construyó su interpretación de las imágenes paleolíticas. Hemos adoptado un enfoque en el que la historia de la arqueología se entrelaza con la historia de la antropología cultural (etnología en Francia), pero no de forma abstracta, sino a partir del pensamiento concreto de Mauss y Leroi-Gourhan. Así, analizamos la categoría "arte paleolítico» como una representación dinámica en el seno de la arqueología prehistórica, muy influida por las modificaciones que se producen en otras categorías desarrolladas por la antropología cultural como las de «primitivo», «arte»y «religión», enfatizando la idea de interdependencia. De hecho, para Leroi-Gourhan la arqueología «no era más que la etnología en el pasado" (Schlanger 2015, 108). Adicionalmente nos preguntamos por la influencia que tuvieron sus ideas y qué parte de su discurso se incorporó al estudio del arte prehistórico por el resto de investigadores. Por último, valoramos si la nueva perspectiva que introdujo Leroi-Gourhan del arte prehistórico desde nociones procedentes de la etnología puede explicarse a partir del concepto de interdisciplinariedad.

\section{Marcel Mauss. El profesor}

Marcel Mauss pertenece a la primera generación francesa de sociólogos y etnólogos comparativistas que, junto con Robert Hertz y Henri Hubert, entre otros, se agruparon desde 1896 bajo la tutela de Émile Durkheim alrededor de la revista Année Sociologique. Pero más allá de su vinculación con su maestro y tío Émile Durkheim, su obra posee un carácter original (Berthoud \& Busin 1996; Brian \& Weber 2014; Damish 2008; Dzimira, 2007; Fournier 1994; Garces \& Alexander 2009; Karsenti 1997; Lévi-Strauss 1950; Richman 2013; Tarot 1999; 2003; Valeri 2013).

La labor docente de Marcel Mauss marcó durante los años veinte y treinta a toda una generación de antropólogos, sociólogos, lingüistas, arqueólogos e historiadores (Dzimira 2007, 21; Fournier 1994, 602). Entre 1930 y 1936 André Leroi-Gourhan fue alumno de Mauss en L'École des Hautes Études, siguiendo sus cursos de «sciences religeuses» y "peuples primitives» y, de forma especial, cinco conferencias sobre los ritos y fiestas estacionales de los Chukchi del extremo este de Siberia (Soulier 2015, 17-18; 2018, 25). Así recordaba en 1982 estos cursos: «nunca éramos más de diez [...] Él tenía una erudición extraordinaria, y nosotros absorbíamos con deleite todo aquello» (Leroi-Gourhan 1982a, 32). Su influencia sobre Leroi-Gourhan fue intensa y destacable en lo referido a la etnografía de las poblaciones árticas: «era asombroso, sobre todo, cuando explicaba textos 
de autores que habían trabajado en Siberia con los guiliacos o los goldos» (Leroi-Gourhan 1982a, 32). Esta herencia se constata tanto en sus primeras obras (e.g. Leroi-Gourhan 1936; 1937), como en la tesis doctoral que años después el propio Mauss le dirigió sobre la arqueología de las poblaciones del norte del Pacífico (Leroi-Gourhan 1946). Leroi-Gourhan nunca dejo de reconocer el legado de Mauss en su pensamiento: «siempre encuentro el mismo placer en la relectura de Mauss. Creo que captó ciertos problemas» (Leroi-Gourhan 1982a, 33).

Uno de los rasgos que mejor definen el pensamiento de Mauss es la redefinición que hizo del «hecho social» a partir de un nuevo diálogo de la etnología con la psicología y la lingüística (Tarot 1999, 271-280). Así, aquello que mejor caracterizó la etnología de Mauss fue su concepción simbólica de la cultura humana (Tarot 1999, 620-622). Para este investigador cualquier «hecho social» estaba construido sobre una red de significados. En el mundo humano todo debía tener sentido. Según Mauss este acto de simbolización era a la vez natural y cultural. La capacidad de simbolizar era inmanente al ser humano y, por tanto, universal, pero como realidad cultural adquiría una expresión particular en cada sociedad. De igual manera, sostuvo que los símbolos formaban un orden propio, ya que unos remitían a otros y no solo a las «realidades» que designaban. Por tanto, los símbolos solo podían existir si formaban una red. Además, para este investigador los símbolos no eran una mera representación intelectual, sino que siempre traducían un estado emocional colectivo.

Es precisamente esta comprensión simbólica de la cultura la que absorbió el joven LeroiGourhan, y la que incorporó años más tarde a su lectura del arte paleolítico como veremos a continuación.

\section{UnA NUEVA CONCEPCión DEL ARTE PALEOLÍ́tico}

La mayor parte de especialistas han considerado que a finales de los ańos cincuenta del siglo xx se produjo un cambio en la manera de conceptualizar el arte paleolítico (Bahn \& Vertut 1997, 189-197; Conkey 1989; 2001; González-Sainz 2005; Lorblanchet 1995, 83-96; White 2003, 56-57). La nueva lectura de este arte descansó sobre tres elementos principales. Primero, la consideración de la gráfica paleolítica como un sistema de símbolos interrelacionados. Segundo, la interpretación de estos símbolos como el reflejo de una mente compleja, y no como la manifestación de un pensamiento primitivo y atrasado. Tercero, la comprensión de las imágenes paleolíticas como la expresión visual de una mitología.

Sin duda, este cambio de paradigma en la forma de interpretar el arte paleolítico es producto de la aproximación que Leroi-Gourhan propició entre la prehistoria y el pensamiento etnológico francés de las décadas centrales del siglo xx. En este sentido, se ha insistido en la filiación de Leroi-Gourhan con la etnología estructuralista de Claude Lévi-Strauss (Bahn \& Vertut 1997, 196; Clottes 2011: 31; Conkey 1989; 2001; Sauvet, 1994, 260-261). Independientemente de la lógica permeabilidad que pudo haber entre estos dos autores contemporáneos, el carácter estructuralista y la influencia de Claude Lévi-Strauss en la obra de Leroi-Gourhan ha sido recientemente discutida, teniendo en cuenta que tuvo muchas otras fuentes de inspiración (Palacio-Pérez \& Moro Abadía 2015; Moro Abadía \& Palacio-Pérez 2015; Palacio Pérez 2017, 132-135). Aquí, queremos destacar cómo la aplicación que Leroi-Gourhan hizo de ideas provenientes de la etnología al estudio del arte prehistórico tuvo como fundamental referente a su maestro Marcel Mauss. 


\subsection{El arte paleolitico como una red simbólica}

Las principales estrategias que aplicó Leroi-Gourhan para estudiar e interpretar el arte paleolítico como un sistema de símbolos (Leroi-Gourhan 1958a; 1958c; 1964 [1976]; 1965 [1970]; 1965 [1971]) se correlacionan con muchas de las indicaciones que señaló Mauss para el estudio del comportamiento estético (Mauss 1903; 1908; 1927, 115-116; 1931; 1947 [1989], 85-122).

Primero, Leroi-Gourhan argumentó que las «imágenes que componen el arte prehistórico son símbolos» (Leroi-Gourhan 1966b, 41). Sostuvo que los animales y los signos del arte paleolítico constituyen un "sistema de referencias simbólicas» (Leroi-Gourhan 1964 [1976], 86). Así, mantuvo el principio establecido por Mauss de que «el dibujo significa lo que quieren hacerle significar las personas, sea geométrico o imite el orden natural» (Mauss 1947 [1989], 104) porque «toda forma dada ofrece un símbolo» (Mauss 1947 [1989], 89). Segundo, Leroi-Gourhan consideró que las representaciones paleolíticas constituyeron «una entidad coherente de la misma manera que lo hace una familia lingüística» (Leroi-Gourhan 1968b, 67). Sugirió que las imágenes del Paleolítico eran un lenguaje suponiendo que «fueron leídas» (Leroi-Gourhan 1982a, 204) por los humanos prehistóricos. Esta interpretación marcó una continuidad con la comprensión de Mauss del arte como frase: «un dibujo no suele presentarse aislado [...] un motivo gráfico implica frases graficas [...] un artista no sólo dice, sino que ordena las cosas» (Mauss 1947 [1989], 104). En tercer lugar, el concepto clave para entender la interpretación que Leroi-Gourhan hizo de las imágenes del Paleolítico fue el de relación. Para la comprensión de este arte las figuras tenían que ser reducidas a «sus relaciones en el espacio y a sus correlaciones» (Leroi-Gourhan 1958c, 516), de tal manera que «si las pinturas y grabados paleolíticos han querido expresar algo [...] las frecuencias observadas han de mostrarlo» (Leroi-Gourhan 1958c, 516). Esta argumentación enlaza directamente con la sugerencia de Mauss de «no estudiar jamás un elemento estético sin mencionar las relaciones de ese elemento con el todo» (Mauss 1947 [1989], 105). En suma, la lectura del arte paleolítico que hizo Leroi-Gourhan, teniendo como base algunas de las ideas de Mauss sobre el comportamiento estético y cultural (Damisch 2008; Richman 2013; Tarot 1999, 620-622), supuso introducir una nueva forma de conceptuar las imágenes prehistóricas, definida por una dimensión simbólica hasta entonces inexplorada.

\subsection{El arte paleolitico como reflejo de una mentalidad compleja}

El concepto de «magia simpática» sirvió para explicar el significado del arte paleolítico durante toda la primera mitad del siglo xx. Así, los investigadores transfirieron al pasado prehistórico una supuesta "mentalidad primitiva», irracional e ilógica, que los antropólogos de finales del siglo XIX habían construido a partir de comparaciones etnográficas hechas entre poblaciones cazadoras-recolectoras contemporáneas (Palacio Pérez 2010a; 2010b; 2013). Leroi-Gourhan criticó esta idea de "primitivo» y de «mentalidad primitiva». Sostuvo que «el primitivo actual [era] capaz de una evolución intelectual propia» (Leroi-Gourhan 1957, 84) y creyó que su arte expresaba "valores humanos en el sentido más general; [...] en un contexto igual de elaborado que el nuestro, pero diferente» (Leroi-Gourhan, 1957, 84). Leroi-Gourhan recogió así una opinión que su maestro Mauss sostuvo durante toda su vida (Tarot 1999, 485-493). Mauss pensó que «no existen pueblos no civilizados, sólo existen civilizaciones diferentes» (Mauss 1902, 43) e insistió en que "las sociedades más simples pueden ser al mismo tiempo las más complejas» (Mauss 1947 [1989], 209). Leroi-Gourhan introdujo esta forma de ver las sociedades cazadoras y recolectoras proveniente de la etnología dentro del campo de reflexión de la prehistoria, lo que le llevó a establecer la complejidad ideológica 
del humano del Paleolítico superior, cuyo arte definió como el reflejo de «un pensamiento creativo singularmente complejo» (Leroi-Gourhan 1958b, 365).

\subsection{Las imágenes paleoliticas y el pensamiento mitico-religioso}

Un aspecto clave en donde conectan las ideas de Leroi-Gourhan y las de Mauss es en la relación estrecha que establecieron entre el origen del arte y la religión (Leroi-Gourhan 1964 [1970], 270-273; Mauss 1947 [1989], 88). Ambos autores basaron la relación entre arte y religión en las emociones humanas. Según Leroi-Gourhan «la vinculación fundamental del arte y la religión es emocional» (Leroi-Gourhan 1964 [1970], 275). Una idea que prácticamente reproducía el pensamiento de Mauss: «la emoción tiene en la [...] representación mítica, así como en el arte [...], un papel considerable» (Mauss 1908, 61). Por tanto, los conceptos de simbología mítico-religiosa y emoción que sirvieron a Leroi-Gourhan para explicar el arte de las sociedades prehistóricas fueron, en parte, una herencia del pensamiento maussiano nacido en el seno de la etnología.

A partir de este planteamiento general, Leroi-Gourhan abordó el problema concreto del sentido de las imágenes paleolíticas. Aunque la interpretación religiosa del arte paleolítico fue una constante en la carrera de Leroi-Gourhan, la forma en que entendió la conexión entre el arte paleolítico y la religión cambió a lo largo del tiempo. En un principio, Leroi-Gourhan sostuvo la teoría de la magia de caza apoyándose en paralelismos con poblaciones árticas contemporáneas. Esta idea la aplicó en La civilisation du renne, un texto en el que estudió la historia cultural de las sociedades árticas y en el que se refirió tangencialmente al arte paleolítico (Leroi-Gourhan 1936, 62-68). Sin embargo, no conviene sobrevalorar este libro inaugural de Leroi-Gourhan sobre el cual afirmó años más tarde: "publiqué una obra singularmente temeraria [...] Mauss me dijo simplemente que se consideraba como una gallina que hubiera puesto un huevo de pato» (Leroi-Gourhan 1982b, 35). Un año después, quizá como resultado de esta crítica, sugirió que la vida y el arte de las poblaciones árticas se organizaba a partir de una mitología compleja «bajo el signo masculino del señor de los espíritus y [...] el principio femenino de (la diosa) Sedna» (Leroi-Gourhan 1937, 91). Es curioso constatar cómo esta idea procedente de su trabajo de etnólogo fue trasferida años más tarde a la explicación del arte paleolítico.

En cualquier caso, a finales de la década de 1950 Leroi-Gourhan, paralelamente a su alumna y colega Annette Laming-Emperaire (1962), comenzó a conceptualizar el arte del Paleolítico de manera diferente (Leroi-Gourhan 1958a; 1958c). Propuso un examen interno de las representaciones artísticas, sin recurrir a analogías etnográficas directas (Leroi-Gourhan 1958a, 307), pero sí a las grandes construcciones comparativas que la etnología había hecho sobre la mente humana (Perlès 1992). Así, a mediados de la década de 1960 Leroi-Gourhan había creado una interpretación del arte prehistórico que mantuvo hasta el final de su vida y en la que se reconoce el eco del pensamiento de Mauss.

Sugirió que las imágenes del paleolítico eran «mitogramas» (Leroi-Gourhan 1966a, 110; 1967, 3). Los mitogramas son «el equivalente gráfico de un mito oral» (Leroi-Gourhan 1967, 3). Esto enlaza directamente con la idea expresada por Mauss de que la figuración artística era el reflejo de una narración verbal. Para este investigador «el rito oral, el mito, y la representación del mito coinciden verdaderamente» (Mauss 1903, 232), siendo «las pinturas rituales [...] la transcripción de diversos mitos» (Mauss 1903).

De esta forma, para Leroi-Gourhan «el arte paleolítico era la expresión [...] de concepciones acerca de la organización natural y sobrenatural del mundo» (Leroi-Gourhan 1965 [1970], 120). Concluyó que «el arte prehistórico gira en torno a un tema probablemente mitológico en el que 
se enfrentan complementariamente imágenes de animales y representaciones de hombres y mujeres» (Leroi-Gourhan 1965 [1970], 266). Según él se trataba de «divinidades masculinas y femeninas, cuyas acciones no aluden abiertamente a la reproducción sexual, pero cuyas cualidades masculinas y femeninas son necesariamente complementarias» (Leroi-Gourhan 1965 [1971], 86). Sin duda, estas explicaciones de Leroi-Gourhan conectan con el pensamiento expresado por Mauss de que «todo hecho religioso y estético forma parte de un sistema [...] de representaciones colectivas características de cada sociedad» (Mauss 1969 [1938], 268). Según él «las representaciones religiosas penetran todo» (Mauss 1947 [1989], 246) y están integradas por imágenes de fenómenos naturales, seres espirituales, mitos y leyendas (Mauss 1947 [1989], 246). Así, el mito expresa una determinada concepción simbólica de la realidad (Hubert \& Mauss 1903, 260) en el que seres y cosas se organizan en categorías complementarias opuestas - invierno y verano, tierra y mar, masculino y femenino, etc.- (Durkheim \& Mauss 1903; Hubert \& Mauss 1908, 192; Mauss \& Beuchat 1906).

Vemos, por tanto, cómo la concepción sostenida por Leroi-Gourhan que veía en el arte paleolítico una simbología mitológica de carácter binario puede explicarse a partir de su conexión con el pensamiento etnológico de tradición maussiana.

\section{El legado de la visión interdisciplinar de André Leroi-Gourhan en la explicación DEL ARTE PALEOLÍ́TICO}

La obra de Leroi-Gourhan, marcada por la aproximación de la prehistoria a la antropología, tuvo un gran reconocimiento en su país, y una difusión importante, pero desigual en diferentes países de Europa y, posteriormente, en Norteamérica. Esto se debió, en gran medida, a la particular configuración del campo científico-institucional francés en torno a grandes investigadores que tienden a controlar ámbitos de conocimiento específicos, lo que permitió a André Leroi-Gourhan adquirir una relevancia y poder notable en el contexto de las incipientes instituciones académicas francesas dedicadas a la prehistoria (Coye 2015; Coye \& Nathalie 2004; Soulier 2003; 2015; 2018). Esto le aseguró los apoyos necesarios para desarrollar y difundir su trabajo a diferentes niveles (científico, editorial, institucional...). Sin duda, su esquema de organización estilística y cronológica del arte paleolítico fue el elemento mejor acogido y permaneció como un modelo a seguir por parte de la mayor parte de investigadores hasta la crítica que sufrió en los últimos años del siglo xx (Lorblanchet \& Bahn 1993), con precedentes anteriores (Ucko \& Rosenfeld 1967). Ahora bien, aquí nos centraremos en cómo influyó su lectura y comprensión del significado del arte paleolítico en la comunidad científica. La lectura que Leroi-Gourhan hizo del arte paleolítico tuvo un impacto muy diferente en función de las distintas tradiciones arqueológicas nacionales. Para ilustrar este hecho evaluaremos su influencia en Francia, España y, de una forma más general, en el ámbito de la arqueología anglosajona.

En el caso francés la influencia de Leroi-Gourhan fue muy intensa dado que su labor docente marcó a toda una generación de prehistoriadores formados entre los años cincuenta y setenta del siglo xx (Soulier 2003; 2015; 2018). De esta forma, entre muchos de los investigadores franceses que han liderado el estudio del arte rupestre desde los años setenta del siglo xx, pueden contarse algunos de sus alumnos y seguidores. Entre ellos cabría citar a Gilles y Brigitte Delluc, Jean Plassard, Robert Bégüen, Denis Vialou o Georges Sauvet. Estos autores han mantenido los principios esenciales de la interpretación que Leroi-Gourhan hizo del arte paleolítico, aunque, al mismo tiempo, han sido críticos con algunas de sus afirmaciones (Delluc \& Delluc 1991; 1999; Leroi-Gourhan 
et al. 1995; Sauvet 1994; Sauvet \& Sauvet 1979; Sauvet et al. 1977; Sauvet \& Wlodarczyk 1995; Vialou 1981; 1986; 1987; 1994). Todos estos especialistas han retenido el carácter simbólico, la disposición estructurada y el significado mitológico del arte paleolítico: «Mito y arte rupestre, utilizando vehículos diferentes, responden a las mismas necesidades. En consecuencia, tenemos que atender a lo que las estructuras universales del pensamiento mítico [...] reflejan en una forma de expresión gráfica» (Sauvet \& Sauvet 1979, 352). Por su parte, las críticas se concentraron en discutir la universalidad de la estructuración binaria propuesta por Leroi-Gourhan. Así, Sauvet ha señalado que las relaciones temáticas son mucho más complejas de lo identificado por Leroi-Gourhan (Sauvet 1994; Sauvet \& Sauvet 1979; Sauvet et al. 1977; Sauvet \& Wlodarczyk 1995). De igual manera, Vialou ha subrayado que "no existe un único estereotipo de cueva decorada» cada cueva se presenta "como un microcosmos diferente construido de manera original» (Vialou 1986, 107). Independientemente de estas críticas puntuales, el modelo general de comprensión del arte paleolítico propuesto por Leroi-Gourhan tuvo una importante continuidad en Francia, estableciendo un claro vínculo entre la etnología simbólica francesa y el estudio del arte prehistórico.

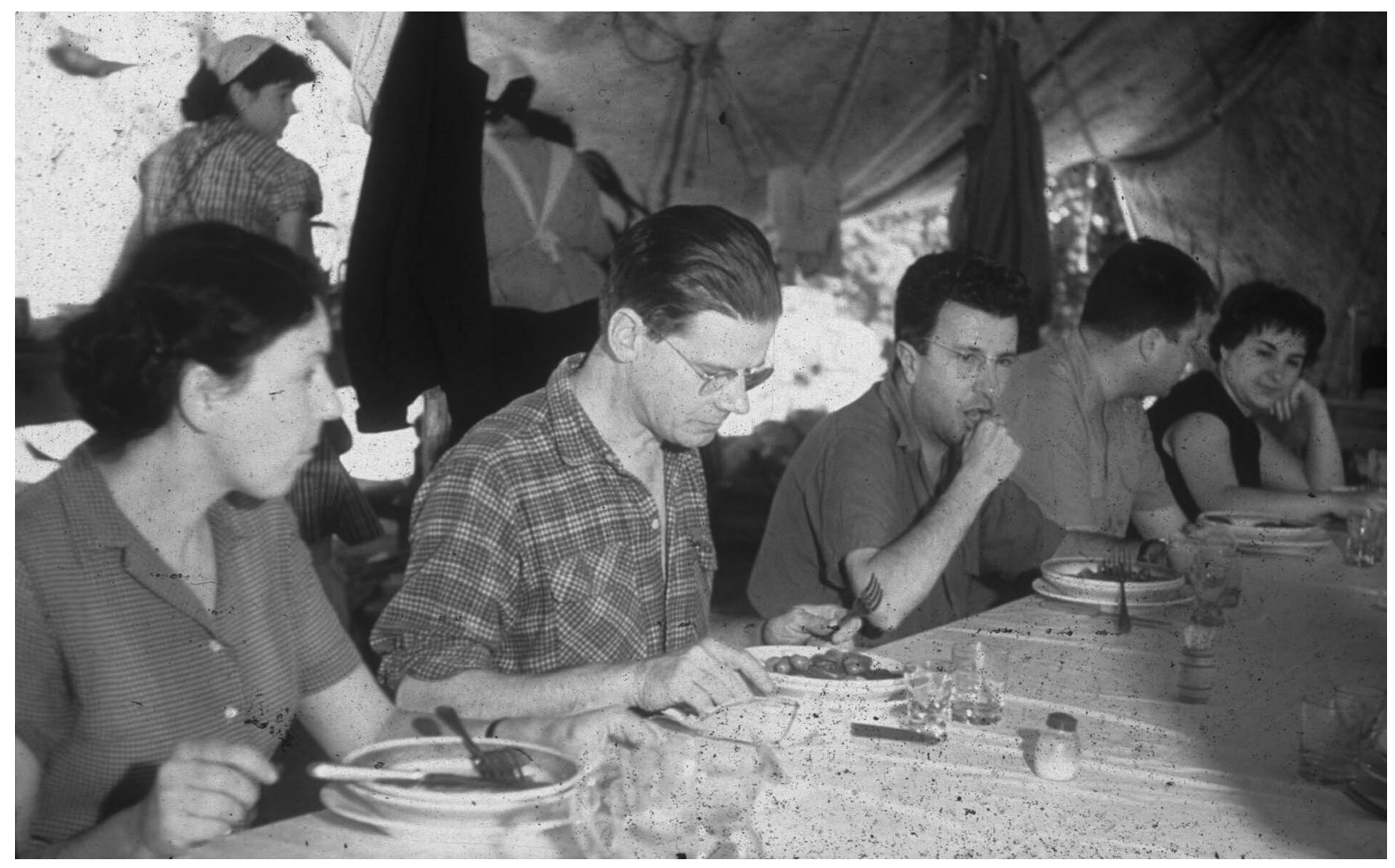

Figura 1. Arlette Leroi-Gourhan y André Leroi-Gourhan en el Curso Internacional de Arqueología celebrado en la Cueva del Pendo (Cantabria, España), en 1957. (Cortesía de Alfonso Moure Romanillo).

En el caso de España, la acogida de las ideas de Leroi-Gourhan referidas al estudio del significado del arte paleolítico fue muy controvertida desde el origen. Las propuestas de Leroi-Gourhan no encajaron bien en la arqueología española de los años del franquismo, definida por su carácter positivista y descriptivo (Díaz-Andreu 1993; Gracia Alonso 2009), estando muy vinculada a pro- 
puestas historicistas más que al ámbito de las generalizaciones etnológicas. Según Almagro Basch, las ideas de Leroi-Gourhan se habían construido sobre «observaciones aisladas en las cuales ha valorado conceptos de tipo freudiano más que objetivos análisis de los datos [...] de la investigación paciente y no de las abstracciones subjetivas, que no conducen a ningún resultado científico» (Almagro Basch 1964, 97). A pesar de ello, el autor francés investigó en España, de hecho, acudió a la edición de 1957 de los "Cursos de arqueología de campo» de la cueva de El Pendo (Cantabria), organizados por Julio Martínez Santa-Olalla (Figuras 1 y 2). Es entonces cuando, acompañado por Joaquín González Echegaray, visitó varias cuevas cantábricas (González Echegaray 1963, 34-35). Precisamente, Joaquín González Echegaray es uno de los primeros investigadores españoles en citar la bibliografía de Leroi-Gourhan en su monografía sobre la cueva de las Chimeneas. En esta obra González Echegaray parafraseó a Leroi-Gourhan mencionando la posible existencia de «principios de composición relacionados con la diversidad sexual y cuya interpretación [...] habría que relacionarla, acaso, con un simbolismo en donde la fecundidad y la caza se encuentran en mutua relación» (González Echegaray 1963, 34). En realidad, la referencia a los planteamientos de LeroiGourhan no dejó de ser una mera nota de erudición bibliográfica, y, si acaso, un intento de recoger las nuevas ideas que comenzaban a difundirse en el ámbito internacional, puesto que, en conjunto, no tuvieron ninguna importancia en la confección de la obra. Como el mismo González Echegaray reconoce «ignoramos cómo puedan explicarse exactamente estos datos dentro de la teoría de LeroiGourhan» (González Echegaray 1963, 34).

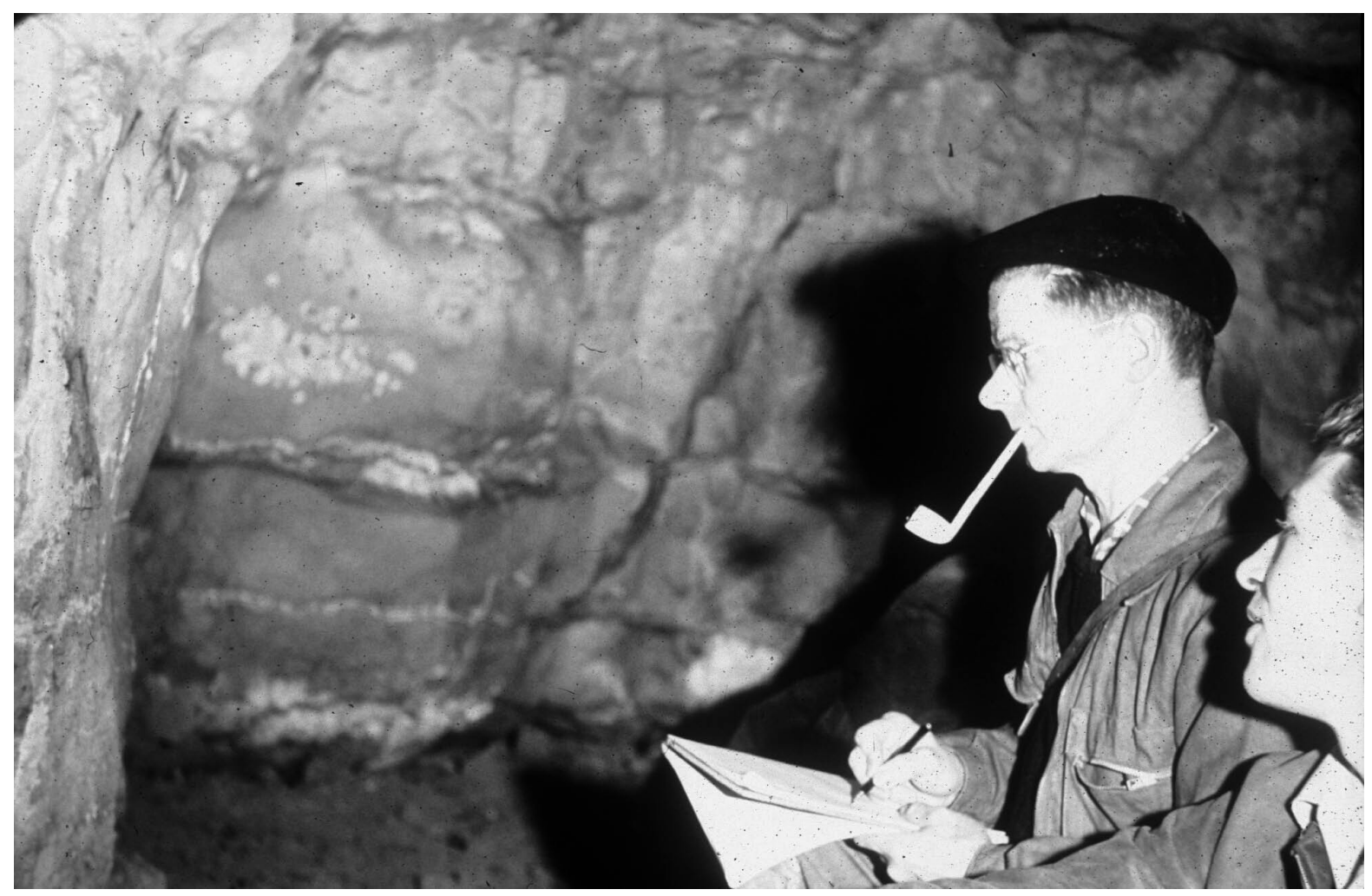

Figura 2. André Leroi-Gouran en la Cueva de Altamira (Cantabria, España), en 1957 (Cortesía de Alfonso Moure Romanillo). 
Este mismo cariz parecen tener algunas de las referencias existentes a las ideas de Leroi-Gourhan en la monografía de la cueva de Altxerri, publicada por José Miguel de Barandiarán, cuando al describir un signo afirma que pudo ser «un símbolo masculino» (Barandiarán 1964, 98). Quizás, pueda tener más importancia la consideración de las representaciones de animales como símbolos de elementos míticos y no como recreaciones realistas de los mismos, aunque, una vez más, la cosa toma cierta ambigüedad al mezclar estas ideas con una supuesta mitología vasca: «las mismas figuras no eran probablemente más que signos, formas visibles de seres invisibles, como aquellos animales (caballos, cabras, toros) que la mitología vasca considera como habitantes de las cavernas» (Barandiarán 1964, 13). Al igual que sucediera con la monografía de Las Chimeneas, en la de Altxerri la influencia de las ideas de Leroi-Gourhan no tiene casi ningún peso en la estructura general de la obra. La opinión más generalizada en estos ańos fue que la obra del autor francés era "puro ensayismo» (Almagro Basch 1964, 97). Este escepticismo de la arqueología española sobre las teorías de Leroi-Gourhan no impidió que participara en algunos de los congresos más importantes que tuvieron lugar en España y disfrutara de la oportunidad de discutir su obra, como sucedió en el Simposio internacional de arte rupestre, celebrado en Barcelona en 1966 (Leroi-Gourhan 1968b), Santander Symposium (Leroi-Gourhan 1972) y Altamira Symposium (Leroi-Gourhan 1980 a; 1980b). La siguiente generación de investigadores españoles que comenzó a florecer a partir de los años ochenta del siglo xx asumió de buen grado algunas de sus ideas principales como el carácter simbólico de las representaciones, la disposición estructurada de los temas y su distribución ordenada a lo largo de la topografía de la cueva. Sin embargo, heredaron las críticas que ya habían hecho algunos autores franceses (Sauvet \& Sauvet 1979; Vialou 1981; 1986) o anglosajones (Ucko \& Rosenfeld 1967), orientadas a rebatir el carácter binario y universal de la propuesta explicativa de Leroi-Gourhan, así como la dificultad de llegar a conocer el sentido último de las representaciones - mitológico o de cualquier otro tipo- cuando se carece del registro inmaterial que les daba sentido (Bueno Ramírez \& De Balbín Behrmann 2001; González-Sainz 2005).

En el contexto de la arqueología anglosajona la obra de Leroi-Gourhan no tuvo mucha trascendencia y solo ha sido valorada positivamente por algunos investigadores a partir de finales de los ańos ochenta del siglo xx (Conkey 1989; 2001). En parte, esto puede deberse a dos razones principales, una de carácter particular y otra general. La primera, está vinculada a la rápida publicación y difusión de una de las críticas mejor fundamentadas a la obra de Leroi-Gourhan. Se trata del texto, de Peter Ucko y André Rosenfeld, Arte Paleolitico (Palaeolithic Cave Art). Una parte importante de esta obra criticó con precisión las bases metodológicas de las propuestas del autor francés, tales como la dificultad para delimitar las áreas topográficas de la cueva, el carácter arbitrario de las asociaciones de motivos, la debilidad estadística de la frecuencia numérica de las representaciones y la deficiente comprensión de los signos (Ucko \& Rosenfeld 1967, 195-213). A esto se sumó un rechazo a la identificación simplista de un simbolismo dual de carácter sexual que, de existir, "sería un sistema complejo de interrelaciones» (Ucko \& Rosenfeld 1967, 234). Por último, los dos autores, teniendo el primero de ellos formación antropológica y siendo ambos conocedores del arte de los aborígenes australianos y de diferentes poblaciones africanas, subrayaron que el análisis del contenido y el contexto no resulta suficiente para alcanzar una interpretación correcta del arte paleolítico, sin poder contar con la experiencia viva y diversa del registro antropológico (Ucko \& Rosenfeld 1967, 246). La segunda razón que explica esta débil difusión de la obra de Leroi-Gourhan se relaciona con el contexto de la arqueología anglosajona de la época. La interpretación del arte paleolítico como una forma de pensamiento mitológico, expresado mediante símbolos, era incompatible con el carácter hegemónico de la Nueva Arqueología en el mundo anglosajón y su «negación de la mente» como fuente de explicación del comportamiento cultural (Conkey 1989, 140). En 
efecto, la Nueva Arqueología se centró en el estudio de los aspectos materiales de la cultura (tecnología, economía...) y no se interesó por la producción simbólica de las sociedades humanas. De hecho, cuando desde este enfoque se prestó atención al estudio del arte paleolítico, este quedó encerrado dentro de realidades materialistas como la demografía, las estrategias de subsistencia, la naturaleza de las redes sociales y la territorialidad (Barton et al. 1994; Gamble 1982; 1990; 1991; Jochim 1983; 1987; Straus 1987; 1992). Como ha señalado Margaret Conkey no deja de resultar irónico que la Nueva Arqueología haya reivindicado sus lazos con la antropología y, sin embargo, haya obviado la conexión con el «más antropológico de los prehistoriadores europeos» (Conkey 1989, 140).

\section{Discusión Y CONCLUSIÓN}

La explicación del arte paleolítico propuesta por Leroi-Gourhan supuso una renovación conceptual que está directamente relacionada con su comprensión de la prehistoria desde un punto de vista interdisciplinar y, más concretamente, con una mirada que trató de integrar la arqueología prehistórica y la etnología dentro de un mismo campo de reflexión. Así, el arte paleolítico, entendido como una red de imágenes mítico-religiosas que se complementan por oposición, es deudora de la influencia que tuvo sobre Leroi-Gourhan el pensamiento etnológico de Marcel Mauss. En particular, la reflexión maussiana sobre la estética, las representaciones colectivas y la naturaleza simbólica de la cultura humana.

Hemos observado cómo la lectura que Leroi-Gourhan hizo del arte paleolítico tuvo una acogida muy diferente en función de las tradiciones arqueológicas de los diferentes países. Así, en Francia se aprecia una continuidad crítica, expresada en el reconocimiento que una parte importante de prehistoriadores hicieron de una tradición de pensamiento que conectó con el desarrollo de la antropología simbólica francesa. En el caso español, las ideas de Leroi-Gourhan fueron recibidas con escepticismo, en el contexto de una arqueología nacional caracterizada por un positivismo descriptivo, y que vio en la obra del autor francés una especulación antropológica que trascendía con mucho lo que podía sustentarse en el análisis empírico de las evidencias arqueológicas. En el ámbito de la arqueología anglosajona, la obra de este autor tuvo escasa influencia, en gran medida, porque la lectura simbólica que Leroi-Gourhan hizo del arte paleolítico chocó con la hegemonía de las ideas de la Nueva Arqueología. Esta, concentrada en explicar el comportamiento humano en términos adaptativos a partir de aspectos materiales de la cultura, ignoró la obra del autor francés que en apariencia mantenía una concepción excesivamente psíquica del comportamiento humano. Esto nos permite constatar cómo, en ocasiones, las fronteras no se establecen entre disciplinas diferentes, sino entre distintas tradiciones y modos de pensar que se desarrollan en el interior de ellas, fomentando puntos de vista y epistemologías contrapuestas dentro del mismo campo de estudio.

Por último, el ejemplo de Leroi-Gourhan y su estudio del arte paleolítico puede ayudarnos a enfrentar la aplicación del concepto de interdisciplinariedad con periodos en los cuales las disciplinas se hallan en proceso de definición y consolidación académica ¿Es posible hablar de interdisciplinariedad en un momento en el que la prehistoria todavía no había establecido límites epistemológicos claros, ni nítidas fronteras académicas?

La aproximación que Leroi-Gourhan estableció entre etnología y prehistoria admite diferentes lecturas en función de cómo entendamos el término interdisciplinariedad (Aboelela et al. 2007; Frodeman et al. 2010; Salter \& Hearn 1996). Podríamos comprenderlo tan solo como la contribución de dos campos de reflexión a la resolución de un problema de investigación (multidiscipli- 
nariedad), como el producto de la integración de conocimientos originarios de dos o más ámbitos diferentes (interdisciplinariedad), o como un conocimiento producido por la unión de expertos de diferentes disciplinas (transdisciplinariedad). Sin embargo, si atendemos al momento en el cual Leroi-Gourhan hizo sus propuestas, nos encontramos en un periodo en el que la prehistoria presenta cierta ausencia de claridad epistemológica y definición académica, como se pone de manifiesto en el carácter limítrofe que adoptó respecto a disciplinas humanísticas (historia, etnología...) y naturales (geología, paleontología...). Cabría preguntarse entonces si esta interdisciplinariedad no es producto de un cierto «amateurismo o voyeurismo intelectual» (Davis 2007). De hecho, en el caso de Leroi-Gourhan su formación diversa en lingüística, etnología, antropología física y paleontología parece corresponderse en origen con un fenómeno de estas características. Ahora bien, no puede limitarse a esto. La prehistoria francesa se había situado desde sus comienzos fuertemente ligada a las ciencias de la tierra de donde tomó algunos de sus conceptos clave (estratigrafía, series evolutivas, facies...). Sin embargo, André Leroi-Gourhan, por su formación de origen, estuvo siempre preocupado por las manifestaciones de la mente humana (eminentemente simbólica) y por el gesto técnico. Ni la simbología, ni el gesto técnico podían deducirse directamente de los restos arqueológicos; así, se vio obligado a apoyarse en amplias construcciones comparativas, en donde los datos de la prehistoria se integraban en un conjunto más amplio de informaciones etnográficas, lingüísticas, sociológicas e históricas, es decir, según su propia terminología, etnológicas.

Así, en pleno proceso de redefinición teórica, metodológica e institucional de la prehistoria, frente a una disciplina excesivamente marcada por su trayectoria naturalista, Leroi-Gourhan se comprometió con una prehistoria particularmente sensible al campo del arte y de lo simbólico. Ello le avocó a valorar, sintetizar y unificar diferentes perspectivas, aproximaciones y métodos tomados de otras disciplinas, teniendo siempre como referente integrador a la etnología.

\section{BibLIOGRAFÍA}

Aboelela, S., E. Larson, S. Bakken, O. Carrasquillo, A. Formicola, S. A. Glied, J. Haas \& K. M. Gebbie, 2007, «Defining interdisciplinary research: conclusions from a critical review of the literature», Health Services Research 42 (1), 329-346.

Almagro Basch, M., 1964, «El problema de la revisión de la cronología del arte rupestre cuaternario, tomo 1», en: E. Ripoll (ed.), Miscelánea en Homenaje al Abate Henri Breuil, Barcelona: Instituto de Prehistoria y Arqueología de la Diputación Provincial, 87-100.

Audouze, F., 1999, «New advances in French prehistory», Antiquity 73 (279), 167-175.

Audouze, F., 2003, «2003. La préhistoire et le CNRS», La revue pour l'histoire du CNRS 8, 1-20.

Baffier, D., F. David, G. Gauche \& M. Orliac, 1988, «André Leroi-Gourhan et l'ethnologie préhistorique», André Leroi-Gourhan ou Les vois de l'Homme, Paris: Albin Michelle, 27-49.

Bahn, P., \& J. Vertut, 1997, Journey through the Ice Age, London: Weidenfeld \& Nicolson.

Barandiarán, J. M. DE, 1964, «La cueva de Altxerri y sus figuras rupestres», Munibe XVI (3-4), 81-143.

Barton, C., G. Clark \& A. Cohen, 1994, "Art as information: Upper Palaeolithic art in western Europe», World Archaeology 26 (2), 185-207.

Berthoud, G., \& G. Busin (eds.), 1996, Mauss: hier et aujourd'bui. XII colloque annuel du Groupe d'étude Pratiques Sociales et Théories (Revue européenne des sciences sociales XXXIV, 105), Paris: Droz.

Bidet, A., 2007, «Le corps, le rythme et l'esthétique sociale chez André Leroi-Gourhan», Techniques \& Culture 48-49, 15-38.

Brian, E., \& F. Weber, 2014, «La place de Mauss dans l'anthropologie mondiale et dans la mémoire de la sociologie française», Trivium 17, 1-10. 
Bueno Ramírez, P., \& R. de Balbín Behrmann, 2001, «Le sacré et le profane: notes pour l'interprétation des graphies préhistoriques péninsulares», Revue archéologique de l'Ouest, supplément 9, 141-148.

Callmer, J., M. Meyer, R. Struwe \& C. Theune-Vogt (eds.), 2006, The beginnings of academic pre-and protohistoric archaeology (1830-1930) in a European perspective, Berlin: Verlag Marie Leidorf.

Clottes, J., 2011, Pourquoi l'art préhistorique?, Malesherbes: Gallimard.

Conkey, M. W., 1989, "The structural analysis of Palaeolithic art», en: C. C. Lambert-Karlovsky (ed.), Archaeological Thought in America, Cambridge: Cambridge University Press, 135-154.

Conkey, M. W., 2001, «Structural and Semiotic Approaches», en: D. S. Whitley (ed.), Handbook of Rock Art Research, Walnut Creek, London, New Delhi: AltaMira Press, 273-310.

Conklin, A. L., 2013, In the Museum of Man: Race, Anthropology, and Empire in France, 1850-1950, New York: Cornell University Press.

Coye, N., 2011, «Une discipline en reconstruction, la préhistoire française de la première moitié du xxe. siècle», Le Genre Humain 50, 199-220.

Coye, N., 2015, "Une pensée en action: André Leroi-Gourhan et la naissance de la préhistoire moderne», en: P. Soulier (ed.), André Leroi-Gourhan, "l'homme tout simplement». [Travaux de la Maison Archéologie \& Ethnologie, René-Ginouvès n. ${ }^{\circ}$ 20], Paris: Éditions de Boccard, 135-144.

Coye, N., \& R. Nathalie, 2004, «André Leroi-Gourhan et les stratégies de diffusion du savoir sientifique», en: F. Audouze \& N. Schlanger (eds.), Autour de l'Homme. Contexte et actualité d'André Leroi-Gourhan, Antibes: Association pour la promotion et la diffusion des connaissances archéologiques (APDCA), 285-300.

Damisch, H., 2008, «Marcel Mauss, l'esthétique et le "phénomène social total”», L'Homme 185-186, 195212.

DAvis, L., 2007, "A grand unified theory of interdisciplinarity», Chronicle of Higher Education 53 (40), B9.

Delluc, B., \& G. Delluc, 1991, L'art pariétal archaïque en Aquitaine. [XVIIIe supplément à Gallia Préhistoire], Paris: CNRS.

Delluc, B., \& G. Delluc, 1999, «El arte paleolítico arcaico en Aquitania. De los orígenes a Lascaux», Edades, Revista de historia 6, 145-165.

Díaz-Andreu, M., 1993, "Theory and Ideology in Archaeology: Spanish Archaeology under the Franco Regime», Antiquity 67 (254), 74-82.

Díaz-Andreu, M., 2012, "France», en: N. Silberman, A. A. Bauer, M. Díaz-Andreu, C. Holtorf \& E. Waterton (eds.), The Oxford Companion to Archaeology. Vol. I, New York: Oxford University Press, 579-583.

Dobres, M.-A., 1999, «Technology's links and chaines: the processual unfolding of technique and technician», en: M. A. Dobres \& C. R. Hoffman (eds.), The social dynamics of technology. Practice, politics, and world views, Washington, London: Smithsonian Institution Press, 125-146.

Durkheim, E., \& M. Mauss, 1903, «De quelques formes primitives de classification. Contribution à l'étude des représentations collectives", L'Année Sociologique 6 (1901-1902), 1-72.

Dzimira, S. 2007, Marcel Mauss, savant et politique, Paris: La Découverte.

Frodeman, R., J. Thompson Klein \& C. Mitcham (eds.), 2010, The Oxford Handbook of Interdisciplinarity, Oxford: Oxford University Press.

Fournier, M. 1994, Marcel Mauss, Paris: Fayard.

Gamble, C., 1982, «Interaction and alliance in Palaeolithic Society», Man 17, 92-107.

Gamble, C., 1990, El poblamiento Paleolítico de Europa traducción castellana de Mònica Tusell (Collecció Crítica/arqueología), Barcelona: Editorial Crítica.

Gamble, C., 1991, "The social context for European Palaeolithic art», Proceedings of the Prehistoric Society 57 (I), 3-16.

Garces, C., \& J. Alexander, 2009, «Mauss Redux: From Warfare's Human Toll to L'homme total», $A n-$ thropological Quarterly 82 (1), 279-309.

Gaucher, G., 1993, «Les écoles de fouille de Leroi-Gourhan», en: A. Duval (ed.), La préhistoire en France. Musées, écoles de fouilles, associations du XIXe siècle a nos jours, Paris: Editions du Comité des Travaux Historiques et Scientifiques, 37-48. 
González-SaInZ, C., 2005, «El punto de vista de los autores estructuralistas: a la búsqueda de un orden en las cuevas decoradas del Paleolítico superior», en: J. González Echegaray \& J. A. Lasheras (eds.), El significado del Arte Paleolítico (Seminario UIMP, Santander, 2002), Madrid: Ministerio de Cultura, Secretaría General Técnica, 181-209.

GonzÁlez Echegaray, J., 1963, Cueva de las Chimeneas. [Excavaciones Arqueológicas en España 21], Madrid: Ministerio de Educación Nacional, Dirección General de Bellas Artes y Servicio Nacional de Excavaciones Arqueológicas.

Gracia Alonso, F., 2009, La arqueología durante el primer franquismo (1939-1956), Barcelona: Bellaterra.

Hubert, H., \& M. Mauss, 1903, "Compte rendu à O. Gruppe, Griechische Mythologie und Religionsgeschichte», L'Année sociologique 6 (1901-02), 254-263.

Hubert, H., \& M. Mauss, 1908, «Introduction à l'analyse de quelques phénomènes religieux», Revue de l'Histoire des Religions 58, 163-203.

Jocнiм, M., 1983, "Palaeolithic cave art in Ecological perspective», en: G. Bailey (ed.), Hunter-Gatherer Economy in Prehistory, Cambridge: Cambridge University Press, 212-219.

Jochim, M., 1987, «Late Pleistocene refugia in Europe», en: O. Soffer (ed.), The Pleistocene Old World: Regional Perspectives, New York: Plenum, 317-332.

Karsenti, B., 1998, "Techniques du corps et normes sociales: de Mauss à Leroi-Gourhan», Intellectica 26-27, 227-240.

Karsenti, B., 1997, L 'homme total. Sociologie, anthropologie et philosophie chez Marcel Mauss, Paris: PUF.

Laming-Emperaire, A., 1962, La signification de l'art rupestre paléolitique, Paris: Picard.

Leroi-Gourhan, A., 1936, La civilisation du Renne, Paris: Gallimard.

Leroi-Gourhan, A., 1937, «La Zoologie mythique des Eskimo. Sélection rituelle des matières animales», La Revue d'Écologie 3, 84-95.

Leroi-Gourhan, A., 1945, «Leçon d'ouverture du cours d'ethnologie coloniale», Les Études rhodaniennes $20(1-2), 25-35$.

Leroi-Gourhan, A., 1946, Archéologie du Pacifique nord. Matériaux pour l'étude des relations entre peuples riverains d'Asie et d'Amérique [Travaux et mémoires 47]. Paris: Institut d'ethnologie.

Leroi-Gourhan, A., 1957, "L'art des primitifs actuels», en: R. Huyghe (ed.), L'art et l'homme Tome 1, Paris: Larousse, 83-87.

Leroi-Gourhan, A., 1958a, "La fonction de signes dans l'art pariétal paléolithique», Bulletin de la Société préhistorique française 55 (5-6), 307-321.

Leroi-Gourhan, A., 1958b, «Les symbolisme des grands signes dans l'art pariétal paléolithique», Bulletin de la Société préhistorique française 55 (7-8), 334-398.

Leroi-Gourhan, A., 1958c, "Répartition et groupement des animaux dans l'art pariétal paléolithique», $B u$ lletin de la Société préhistorique française 55 (9), 515-528.

Leroi-Gourhan, A., 1961, «L'histoire sans texte: ethnologie et préhistoire», en: C. Samaran (ed.), L'histoire et ses méthodes, Paris: La Pléiade, 217-249.

Leroi-Gourhan, A., 1964 [1970], Le geste et la parole, I- Technique et langage, Paris: Albin Michel.

Leroi-Gourhan, A., 1964 [1976], Les religions de la préhistoire (Paléolithique), Paris: PUF.

Leroi-Gourhan, A., 1965 [1970], Le geste et la parole, II - La mémoire et les rythmes, Paris: Albin Michel.

Leroi-Gourhan, A., 1965 [1971], Préhistoire de l'art occidental. Paris: Mazenod.

Leroi-Gourhan, A., 1966a, «La religion des cavernes: magie ou métaphysique?», Sciences et avenir 228, 106-111.

Leroi-Gourhan, A., 1966b, «Réflexions de méthode sur l'art paléolithique», Bulletin de la Société Préhistorique Française 63 (1), 35-49.

Leroi-Gourhan, A., 1967, "Une nouvelle signification de l'art Paléolithique», Bulletin de la société des explorateurs et des voyageurs français 19, 1-7.

Leroi-Gourhan, A., 1968a, «L'expérience ethnologique», en: J. Poirier (ed.), Ethnologie générale, Paris: Gallimard 1816-1825. 
Leroi-Gourhan, A., 1968b, «Les siges pariétaux du Paléolithique franco-cantabrique», en: E. Ripoll Perelló (ed.), Simposio Internacional de Arte Rupestre (Barcelona, 1966), Barcelona: Diputación Provincial de Barcelona, 67-77.

Leroi-Gourhan, A., 1972, "Considérations sur l'organisation spatiale des figures animales dans l'art pariétal paléolithique», en: M. Almagro Basch \& M. A. García Guinea (eds.), Santander Symposium: actas del Symposium internacional de arte rupestre, Santander, Madrid: Consejo Superior de Investigaciones Científicas, 281-308.

Leroi-Gourhan, A., 1980a, «El gran techo de Altamira y sus santuarios superpuestos», en: M. Almagro Basch \& M. Fernández-Miranda (eds.), Altamira Symposium. Symposium Internacional Sobre Arte Prehistórico (1. 1979. Madrid), Madrid: Ministerio de Cultura, 277-288.

Leroi-Gourhan, A., 1980b, «Les signes parietaux comme «marqueurs» ethniques», en: M. Almagro Basch \& M. Fernández-Miranda (eds.), Altamira Symposium. Symposium Internacional Sobre Arte Prehistórico (1. 1979. Madrid), Madrid: Ministerio de Cultura, 289-294.

Leroi-Gourhan, A., 1982a, The Dawn of European Art. An Introduction to Palaeolithic Cave Painting, Cambridge: Cambridge University Press.

Leroi-Gourhan, A., 1982b, Les racines du monde. Entretiens avec Claude-Henri Rocquet, Paris: Pierre Belfond.

Leroi-Gourhan, A., B. Delluc \& G. Delluc, 1995, Préhistoire de l'art occidental. Nouvelle édition revue et augmentée par Brigitte et Gilles Delluc, Paris: Éditions Citadelles \& Mazenod.

LÉvi-Strauss, C., 1950, «Introduction à l'oeuvre de Marcel Mauss», en: M. Mauss, Sociologie et Anthropologie, Paris: PUF, IX-LII.

Lorblanchet, M., 1995, Les Grottes ornées de la Préhistoire. Nouveaux Regards, Paris: Ed. Errance.

Lorblanchet, M., \& P. Bahn (eds.). 1993, Rock Art Studies: The Post-Stylistic Era, Oxford: Oxbow.

Mauss, M., 1902, "L'enseignement de l'histoire des religions des peuples non civilisés à l'École des Hautes Études. Leçon d'ouverture», Revue de l'Histoire des Religions 45, 36-55.

Mauss, M., 1903, «Compte rendu à F. Boas, The Mythology of the Bella Coola Indians and C. Lumholtz, The Symbolism of the Huichol Indians», L'Année sociologique 1902-1903 (6), 247-253.

Mauss, M., 1908, "L'art et le mythe d'après M. Wundt», Revue philosophique de la France et de l'étranger 66, 48-78.

Mauss, M., 1927, «Divisions et proportions des divisions de la sociologie», L'Année Sociologique, nouvelle série 2 , 98-176.

Mauss, M., 1931, «Les arts indigènes», Lyon Universitaire 14, 1-2.

Mauss, M., 1938 [1969], "Leçons sur les rapports entre certains jeux et cosmologies archaïques (19371938)», Oeuvres, vol. 2. Marcel Mauss, Paris: Minuit, 266-268.

Mauss, M., 1947 [1989], Manuel d'ethnographie. Paris: Payot.

Mauss, M., \& H. Beuchat, 1906, «Essai sur les variations saisonnières des sociétés eskimos. Étude de morphologie sociale», L'Année Sociologique 9 (1904-1905), 39-132.

Moro Abadía, O., \& E. Palacio-Pérez, 2015, «Rethinking the Structural Analysis of Palaeolithic Art: New Perspectives on Leroi-Gourhan's Structuralism», Cambridge Archaeological Journal 25 (3), $657-$ 672.

Nissani, M., 1995, «Fruits, Salads, and Smoothies: A Working definition of Interdisciplinarity», The Journal of Educational Thought 29 (2), 121-128.

Olivier, L., 1999, «The origins of French archaeology», Antiquity 73 (279), 176-183.

Palacio PÉrez, E., 2010a, "Cave art and the theory of art: the origins of the religious interpretation of Palaeolithic graphic expression», Oxford Journal of Archaeology 29 (1), 1-14.

Palacio PÉrez, E., 2010b, «Salomon Reinach and the religious interpretation of Palaeolithic art», Antiquity 84, 853-863.

Palacio PÉrez, E., 2013, «The Origins of the Concept of 'Palaeolithic Art': Theoretical Roots of an Idea», Journal of Archaeological Method and Theory 20 (4), 682-714.

Palacio Pérez, E., 2017, El arte paleolítico. Historia de una idea, Santander: Nadir. 
Palacio Pérez, E., \& O. Moro Abadía, 2015, «Le symbole face à l'évolution: André Leroi-Gourhan et l'art paléolithique», en: P. Soulier (ed.), André Leroi-Gourhan, "l'homme tout simplement ". [Travaux de la Maison Archéologie \& Ethnologie, René-Ginouvès n²0], Paris: Éditions de Boccard, 145-158.

Perlès, C., 1992, "André Leroi-Gourhan et le comparatisme», Les Nouvelles de l'archéologie [Dossier: Audouze, F., Schnapp, A (eds.) Un homme, une ouvre: Leroi-Gourhan] 48-49, 23-30.

Richman, M., 2013, «Marcel Mauss on Art and Aesthetics: The Politics of Division, Isolation, and Totality", en: A. Reley, W. S. F. Pickering, W. W. Miller (eds.), Durkheim, The Durkheimians and the Arts, New York and Oxford: Durkheim Press and Berghahn Books, 133-153.

Salter, L., \& A. M. V. Hearn (eds.). 1996, Outside the Lines: Issues in Interdisciplinary Research, Montreal: McGill-Queens University Press.

Sauvet, G., 1994, «Rhétorique de l'image préhistorique», en: A. Fine, R. Perron, F. Sacco (eds.), Préhistoire et Psychanalyse, Paris: PUF, 84-182.

Sauvet, G., \& S. Sauvet, 1979, «Fonction sémiologique de l'art pariétal animalier franco-cantabrique», Bulletin de la Société préhistorique française 76, 340-354.

Sauvet, G., S. Sauvet \& A. WlodarczyK, 1977, «Essai de sémiologie préhistorique (pour une théorie des premiers signes graphiques de l'homme)", Bulletin de la Société préhistorique française 74, 545-558.

Sauvet, G., \& A. WlodarczyK, 1995, "Eléments d'une grammaire formelle de l'art pariétal paléolithique», L'Anthropologie 99 (2-3), 193-211.

Schlanger, N., 2015, "L'insaisissable technologie d'André Leroi-Gourhan. Des tendances et des faits des années 1930 à l'après-guerre», en: P. Soulier (ed.), André Leroi-Gourhan, l'homme, tout simplement. [Travaux de la MAE], Paris: Boccard, 103-116.

Schlanger, N., 2016, «Back in business. History and evolution at the new Musée de l'Homme», Antiquity 90, 1090-1099.

Schlanger, N., 2017, «Leroi-Gourhan joint le geste à la parole», 1964: Leroi-Gourhan.

Schnapp, A., \& P. Lemonnier, 2009, "André Leroi-Gourhan et Pierre Francastel», Histoire de l'art et anthropologie, Les actes de colloques du Musée du Quai Branly Jacques Chirac, Paris: Musée du Quai Branly, $1-24$.

Soulier, P., 2003, "André Leroi-Gourhan (25 août 1911-19 février 1986)», Revue pour l'histoire du CNRS $8,54-68$.

Soulier, P., 2015, «André Leroi-Gourhan (1911-1986), un anthropologue encyclopédiste au xxe siècle», en: P. Soulier (ed.), André Leroi-Gourhan, «l'homme tout simplement». [Travaux de la Maison Archéologie \& Ethnologie, René-Ginouvès n²0], Paris: Éditions de Boccard, 15-46.

Soulier, P., 2018, André Leroi-Gourhan. Une vie [1911-1986], Paris: CNRS Éditions.

Straus, L. G., 1987, «The Palaeolithic Cave Art of Vasco-Cantabrian Spain», Oxford Journal of Archaeology $6(2), 149-163$.

Straus, L. G., 1992, Iberia before the Iberians, Albuquerque: University of New Mexico Press.

Tarot, C., 1999, De Durkheim à Mauss, l'invention du symbolique, Paris: La Découverte.

Tarot, C., 2003, Sociologie et anthropologie de Marcel Mauss, Paris: La Découverte.

Ucко, P., \& A. Rosenfeld, 1967, Arte paleolítico. [Biblioteca para el hombre actual], Madrid: Guadarrama.

Valeri, V., 2013, "Marcel Mauss and the New Anthropology», Journal of Ethnographic Theory 3 (1), 262-86.

Vialou, D., 1981, L'art des grottes en Ariège magdalenienne vols. 1-3, Paris: Museum National d'Histoire Naturelle. Musée de l'Homme.

Vialou, D., 1986, L'art des grottes en Ariège magdalenienne, Paris: CNRS.

Vialou, D., 1987, L'art des cavernes. Les sanctuaires de la Préhistoire, Paris: Le Rocher.

Vialou, D., 1994, «Sexualité et art préhistorique», en: A. Fine, R. Perron \& F. Sacco (eds.), Préhistoire et Psychanalyse, Paris: PUF, 151-171.

White, R., 2003, L'art préhistorique dans le monde, Paris: La Martinière. 